\title{
Comparison of tensile properties between natural fibres and inorganic fibres for strengthening timber structures
}

\author{
Nor Ashiqeen Jamaluddin ${ }^{1}$, Shujaatullah Sheikh', Umar Abdul Hanan ${ }^{1}$, Nur Izzah \\ Mokhtar ${ }^{3}$, Shukur Abu Hassan ${ }^{1,2 *}$, Mohd Yazid Yahya ${ }^{1,2}$, Yusof $\mathrm{Ahmad}^{3}$, Balqis Omar $^{3}$, and \\ Abdul Rahman Mohd. Sam ${ }^{3}$ \\ ${ }^{1}$ School of Mechanical Engineering, Universiti Teknologi Malaysia, 81310 Johor Bahru, Johor, \\ Malaysia \\ ${ }^{2}$ Centre for Advanced Composite Materials (CACM), Universiti Teknologi Malaysia, 81310 Johor \\ Bahru, Johor, Malaysia \\ ${ }^{3}$ School of Civil Engineering, Universiti Teknologi Malaysia, 81310 Johor Bahru, Johor, Malaysia
}

\begin{abstract}
Fibre-reinforced polymers (FRPs) have been successfully applied to the strengthening of reinforced concrete structures and a similar methodology is adopted by researchers in order to strengthen timber structures using synthetic fibres such as carbon, glass or aramid fibres. This paper explores the viability of using fibres from botanical sources for the reinforcement of timber structures. In this study, two natural fibre materials, namely kenaf and ramie, in combination with a polymeric matrix, are tested for their tensile properties in accordance with ASTM D 4018-99. The results indicate that kenaf fibres exhibit average ultimate tensile strength value at rupture of $750 \mathrm{MPa}$ and Young's modulus of 58 $\mathrm{GPa}$. The test results also show that the corresponding parameters for ramie fibres average at $810 \mathrm{MPa}$ and $36 \mathrm{GPa}$ respectively. These values are closer to those of timber as opposed to analogous values for carbon and glass fibres. The strength and elastic moduli compatibility of both kenaf and ramie fibres with timber and contrast with carbon and glass fibres is further discussed in relation to the viability of using these natural fibres as reinforcement for timber.
\end{abstract}

\section{Introduction}

Flexural strengthening of concrete beams with FRP has been extensively studied, for example by Teng et al. [1], and Saadatmanesh and Malek [2]. The American code ACI 440.2R-02 [3] gives detailed guidance on the flexural strengthening of reinforced concrete beams by bonding FRP reinforcement to the tension faces of these beams. A method to calculate the flexural design strengths of these beams is expounded with emphasis on

*Corresponding author: shukur@utm.my 
ductility and serviceability. Relevant strength reduction factors are also given in this code to provide adequate levels of safety against various modes of failure.

Similarly, Technical Report No. 55 [4] explains the advantages of using FRP over the more traditional method of steel plate installation for structural strengthening of concrete structures.

By following a similar line of thinking, engineering researchers have been trying to replicate the success story of FRP-concrete composites to analogous systems involving FRP and timber. Garcia et al. [5] reinforced beams from the timber species Pinus sylvestris with carbon fiber fabrics. These beams were tested under three-point bending to failure. The authors reported that carbon fiber reinforced beams exhibited higher stiffness and load carrying capacity when compared with their unreinforced counterparts.

Other researchers [6-9] have also experimented by bonding carbon, glass and aramid fabrics using adhesives onto the surfaces of timber beams and testing these beams for flexural strength enhancement. Generally, these investigators reported improvements at the moment carrying capacity of the timber-adhesive-fiber composite beam system. The stiffness of the reinforced timber beam, as a rule, also improved. Additionally, a more desirable compressive failure mode was observed [9].

Even as a plethora of research has focused on fortifying reinforced concrete and timber structures with synthetically produced fibers, a new breed of engineering academics and scholars is earnestly looking into the possibility of strengthening structures using fibers from botanical sources. This paper attempts to explore the suitability of using fibers from botanical sources for the reinforcement of timber structures.

\section{Materials and methods}

\subsection{Materials}

Two types of natural fiber filaments were tested under uniaxial tensile loading. Untreated kenaf (binomial name: Hibiscus cannabinus) and untreated ramie (binomial name: Boehmeria nivea) fibers were prepared for testing following ASTM D 4018-99 [10], which is a standardized method for determining the tensile strength and elastic modulus of a resinimpregnated and consolidated carbon fiber tow. Table 1 shows a summary of the mass per unit length (MUL) and densities of the fiber tows used in this study. Meanwhile, Fig. 1 shows the raw materials from which the fiber tows were extracted for each type of fiber.

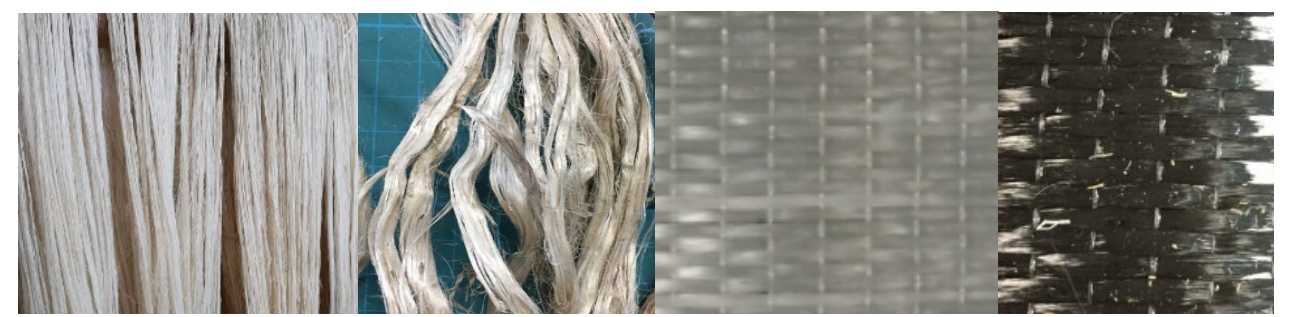

(a)

(b)

(c)

(d)

Fig. 1. Material under study; (a) untreated Ramie, (b) untreated Kenaf, (c) S-Glass, and (d) Carbon UD 300 .

The untreated ramie fibers were sourced from Konsorsium Ramie Indonesia (KORI), while untreated kenaf fibers were supplied by the Malaysian Agricultural Research and Development Institute (MARDI). For the sake of comparison, test specimens made from continuous filament carbon tow and continuous filament glass tow were also prepared 
alongside those of untreated kenaf and untreated ramie fibers. Carbon fibers were extracted from proprietary unidirectional carbon fabric sheets designated as Carbon UD 300 supplied by Polymer Technologies Pte Ltd. Glass fibers were obtained from glass fabric sheets used for structural strengthening supplied by Sika Malaysia and designated as S-Glass.

Table 1. Mass and densities of fibre tows.

\begin{tabular}{|c|c|c|}
\hline Sample type & MUL average (g/m) & Density $\left(\mathbf{g} / \mathbf{c m}^{3}\right)$ \\
\hline Untreated Ramie & 0.589 & 1.25 \\
\hline Untreated Kenaf & 0.708 & 1.19 \\
\hline Carbon UD 300 & 1.616 & 1.79 \\
\hline S-Glass & 1.124 & 2.56 \\
\hline
\end{tabular}

\subsection{Sample preparation}

Samples were cut into $70 \mathrm{~mm}$ lengths as fiber tows. Length and mass of the untreated ramie and kenaf tows were measured and recorded to determine the density and mass per unit length of the tows, which would serve as supplementary data for tensile property computations. The MUL of the samples was calculated by averaging over the results from 5 specimens.

Three sets of apparatus were required. One set was for resin impregnation of the fiber. The second set was for curing the resin-impregnated specimens, and the third one was for tensile testing of the resin-impregnated and consolidated specimens.

A mold shown schematically in Fig. 2 was used as an optional apparatus for applying end tabs to the specimens. Tows prepared for this experiment needed to be impregnated with epoxy. The required distance between tabs was $150 \mathrm{~mm}$ [10]. The authors designed the dimensions of the mold to cater for the size of specimens needed for this test.

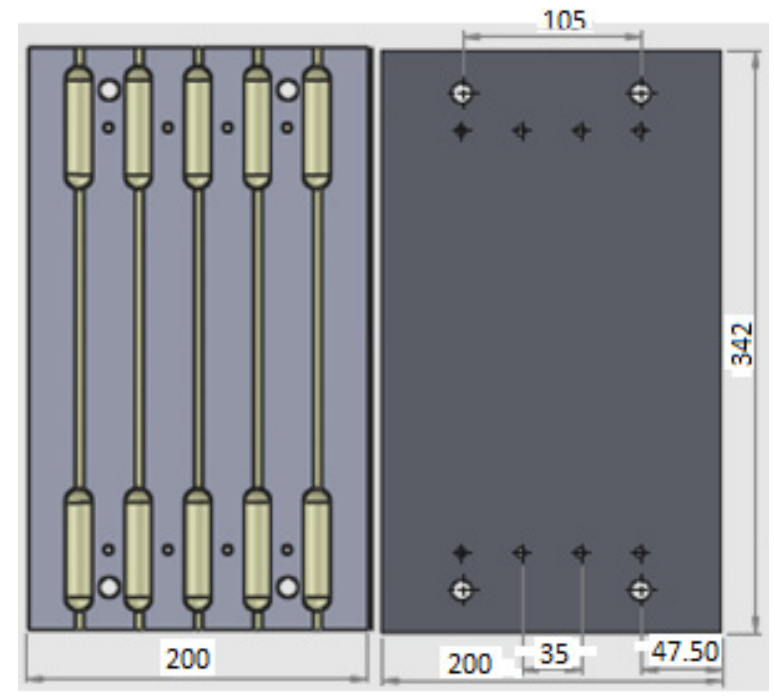

Fig. 2. Male and female mould diagram.

Fiber tow specimens were placed in the mould, and two hexagonal nuts were used to tie both ends of the specimens securely in the mold as shown in Fig. 3 (a). After placing the 
fiber tow samples in the mold, the other half of the mold was then positioned and tightened using bolts and nuts. A proprietary 10:6 epoxy was used for resin impregnation. The goal of the resin impregnation apparatus was to apply and uniformly impregnate resin into the fiber. During the injection stage, a syringe was used to inject the epoxy solution through small holes on top of the mold as shown in Fig. 3 (b). This injection process continued until the epoxy solution filled the mold. This was ascertained when the excess epoxy solution was observed to flow out of the holes at the top surface of the mold. This also indicated that air trapped inside the mold had been completely forced out. The mold was then left for a day to allow for the solidification of the epoxy solution.

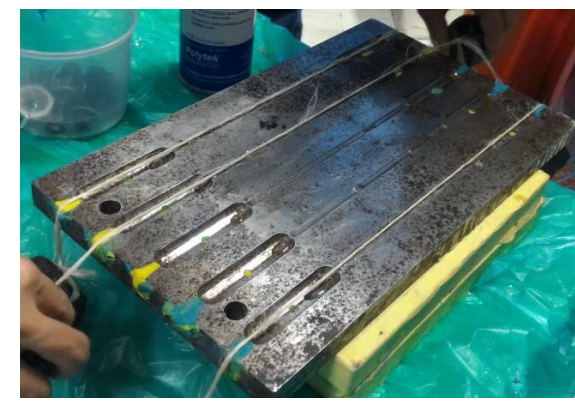

(a)

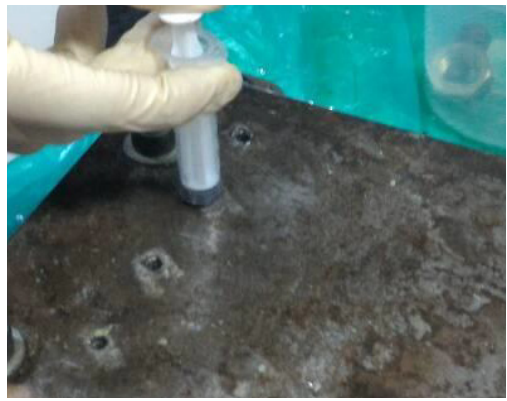

(b)

Fig. 3. (a) Placing fibre tow into the mould and (b) injecting epoxy into the mould.

\subsection{Test methods}

The test methods include procedures for determining the tensile strength and modulus of a resin-impregnated and consolidated fiber tow. The test methods are intended for the testing of fibers that have been specifically developed for use as reinforcing agents in advanced composite structures. The test results of an impregnated and consolidated fiber should be representative of the strength and modulus that are available in the material when used as intended. The performance of fibers in different resin systems can vary significantly, so correlations between results using these test methods and composite testing may not always be obtained. The strain capability of the consolidated resin shall be at least twice the strain capability of the fiber [10].

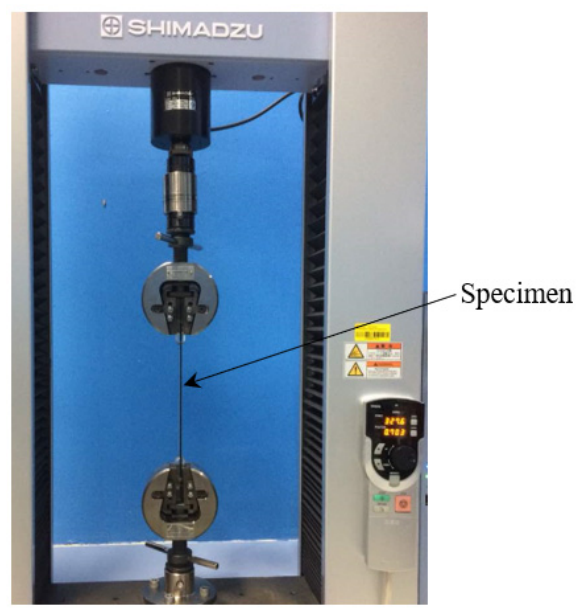

Fig. 4. Testing set-up. 
To complete the test, a few equations as stipulated in ASTM D 4018 need to be applied to determine the tensile strength and Young's moduli of the fiber tows.

The test was conducted at the Centre for Advanced Composite Materials (CACM) Laboratory, Universiti Teknologi Malaysia (UTM). A Shimadzu universal testing machine with a maximum capacity of $10 \mathrm{kN}$ and associated Trapeziumx software was used. The tests were conducted with a crosshead speed of $1 \mathrm{~mm} / \mathrm{min}$. Test specimens were fixed to the machine as shown in Fig. 4. The specimens were then loaded up to failure, and the maximum failure load for each specimen was recorded. The results obtained from this test were then used to calculate the ultimate tensile strength (UTS) and chord moduli of the fiber tows.

\section{Results and discussion}

The load versus displacement curves for all groups of samples are presented in Fig. 5. The important parameters such as ultimate tensile strength, strain at rupture, and tensile moduli are listed in Table 2.

Table 2. Samples tensile test results.

\begin{tabular}{|c|c|c|c|c|c|}
\hline Specimen & $\begin{array}{c}\text { Tensile } \\
\text { strength } \\
\mathbf{( M P a )}\end{array}$ & $\begin{array}{c}\text { Tensile } \\
\text { modulus } \\
\mathbf{( G P a )}\end{array}$ & $\begin{array}{c}\text { Tensile } \\
\text { strain } \\
(\boldsymbol{\mu \varepsilon})\end{array}$ & $\begin{array}{c}\text { Maximum } \\
\mathbf{f o r c e}(\mathbf{k N})\end{array}$ & $\begin{array}{c}\text { Maximum } \\
\text { displacement } \\
(\mathbf{m m})\end{array}$ \\
\hline $\begin{array}{c}\text { untreated } \\
\text { Ramie }\end{array}$ & 810.24 & 36.09 & 22.45 & 389.11 & 3.9713 \\
\hline $\begin{array}{c}\text { untreated } \\
\text { Kenaf }\end{array}$ & 750.14 & 58.47 & 12.93 & 442.58 & 2.2438 \\
\hline S-Glass & 2536.12 & 67.28 & 37.70 & 1113.51 & 6.6431 \\
\hline $\begin{array}{c}\text { Carbon } \\
\text { UD 300 }\end{array}$ & 4736.62 & 133.84 & 35.39 & 2155.16 & 6.2147 \\
\hline
\end{tabular}

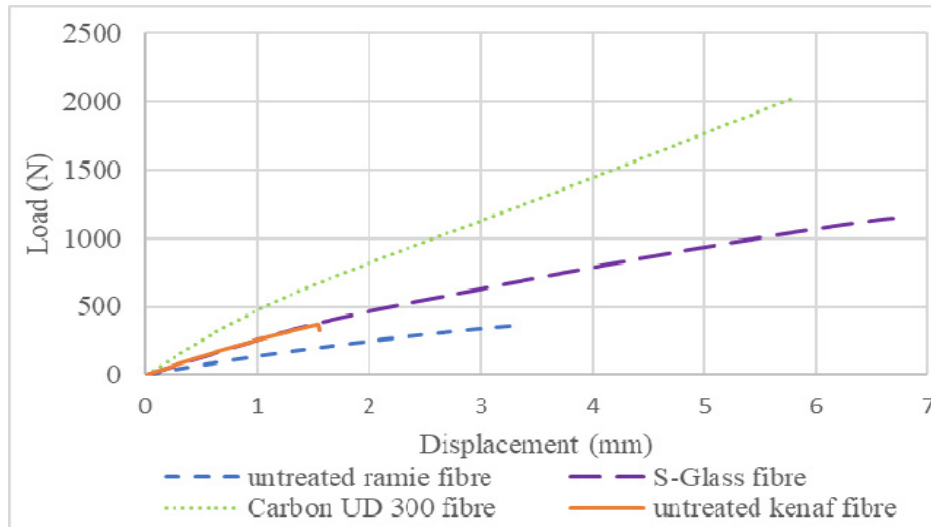

Fig. 5. Graph of tensile load versus displacement for natural and synthetic fibres.

The load-displacement curves in Fig. 5 shows almost straight lines which represent virtually linear stress-strain relationships for all the fibers tested, whether natural organic 
fibers or synthetic inorganic ones. Fig. 5 also shows that Carbon UD 300 has the highest mechanical properties for both tensile strength and tensile modulus, whereas untreated kenaf and untreated ramie fibers pale miserably in comparison. However, compared with SGlass fibers, untreated kenaf fibers have almost the same chord modulus, only $13 \%$ lesser. Meanwhile, untreated ramie fibers exhibit average chord modulus value which is approximately $53 \%$ that of S-Glass.

As a natural fiber, untreated kenaf exhibits better mechanical properties compared with untreated ramie. It has higher ultimate tensile strength and tensile modulus. On a flipside, however, untreated kenaf fibers seem to possess lower ductility compared with their ramie counterparts. Fig. 6 shows the tensile stress values at rupture and tensile chord moduli of the fibers.

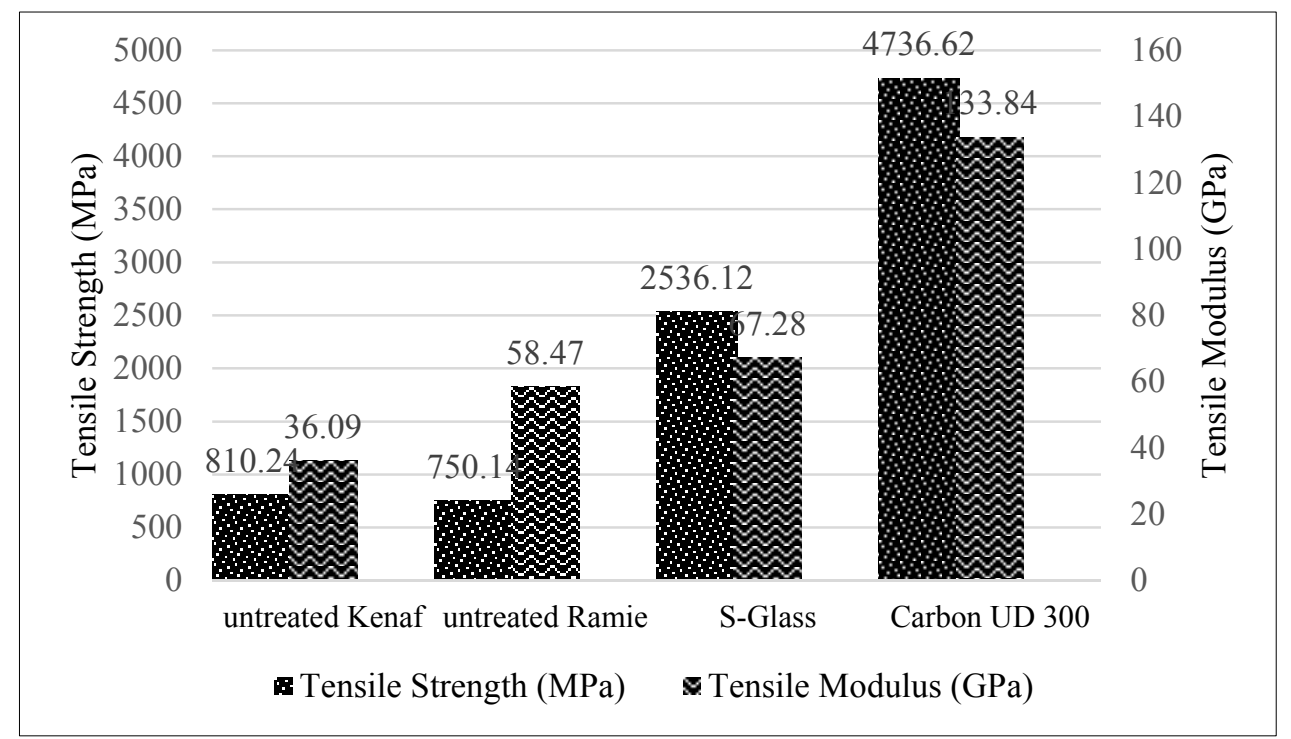

Fig. 6. Graph of tensile strength and tensile modulus for all sample groups.

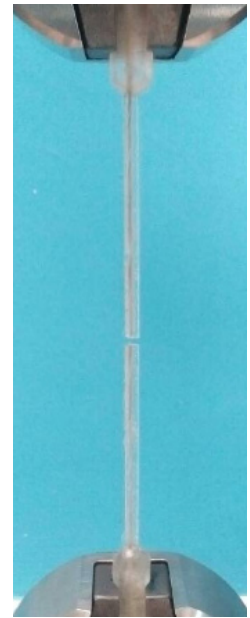

(a)

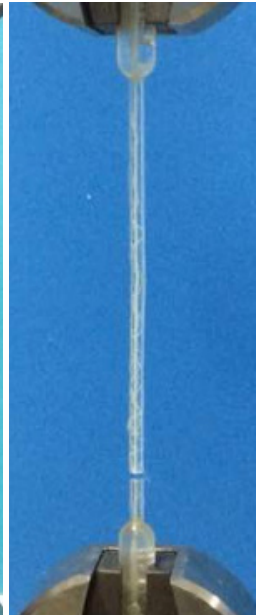

(b)

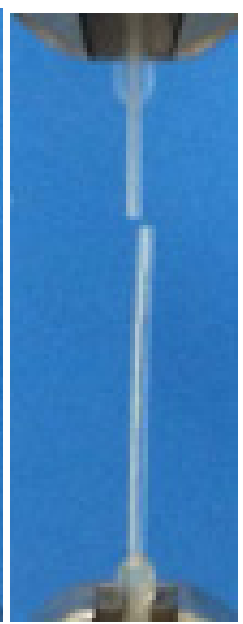

(c)

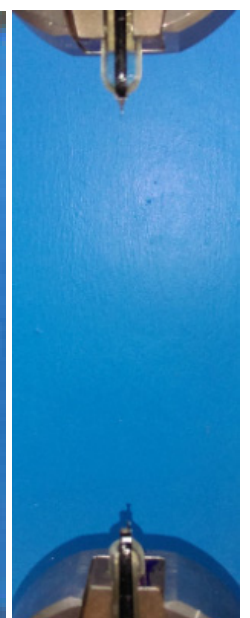

(d)

Fig. 7. Failure modes; (a) untreated Kenaf, (b) untreated Ramie, (c) S-Glass, and (d) Carbon UD 300. 
When compared against synthetic fibers, kenaf, and ramie fibers fare dismally, with their tensile strength values at rupture being a fraction of those of glass and carbon fibers. Nevertheless, the tensile moduli of untreated kenaf and ramie fibers are not that inferior to that of glass fibers. As mentioned earlier, the tensile modulus of kenaf fibers, when compensated for statistical variations, is almost that of glass fibers. This suggests that kenaf fibers may prove an adept substitution for glass fibers in composite materials, barring, of course, other concerns such as fabric wettability, fabric breakage, moisture absorption, and fabric-matrix bond and slippage issues. The tensile chord modulus of untreated ramie fibers, on the other hand, is almost half that of glass fibers.

Fig. 7 shows the failure mode for each sample as outlined in ASTM D 4018-99. The failure mode code has three parts as shown in Table 3. Referring to the table, untreated kenaf specimens as in Fig. 7 (a) generally have failure mode code such as LVM (lateral, various, middle). Meanwhile, untreated ramie fiber specimens as in Fig. 7 (b) mostly have failure mode code LVB (lateral, various, bottom). S-Glass is shown in Fig. 7 (c) exhibits failure mode LVT (lateral, various, top), whereas Carbon UD 300 in Fig. 7 (d) exhibits failure mode XGV (explosive, at the grip, various). The explosive failure mode for carbon indicates that it is a highly brittle material.

Table 3. Three characters of specimen failure mode [10].

\begin{tabular}{|c|c|c|c|c|c|}
\hline \multicolumn{2}{|c|}{ First character } & \multicolumn{2}{c|}{ Second character } & \multicolumn{2}{c|}{ Third character } \\
\hline Failure type & Code & Failure type & Code & Failure type & Code \\
\hline Grip/ tab & G & Inside/grip/tab & I & Bottom & B \\
\hline Lateral & L & At grip/tab & G & Top & T \\
\hline Grip/ tab & G & Inside/grip/tab & I & Bottom & B \\
\hline Lateral & L & At grip/tab & G & Top & T \\
\hline Long splitting & $\mathrm{S}$ & $>1$ w from grip/ & W & Middle & M \\
\hline Explosive & $\mathrm{X}$ & Tab pullout & P & Various & V \\
\hline Other & $\mathrm{O}$ & various & V & Unknown & U \\
\hline
\end{tabular}

\section{Conclusions}

The present experimental work shows that ramie fibers, in combination with a suitable matrix, could be used as a potential reinforcing material for the strengthening of timber structures. Even though its ultimate tensile strength at rupture of $810 \mathrm{MPa}$ is almost onethird that of glass fibers, and a mere fraction that of carbon fibers, its tensile modulus is quite near to that of glass fibers. In structural timber engineering, limiting deflection is often the overriding design criterion rather than that of strength. Therefore, it would be redundant and wasteful to reinforce timbers with tensile strengths in the range of 20 to 30 $\mathrm{MPa}$ with glass and carbon fibers having tensile strengths which are more than 100 times higher.

The compatibility of the tensile moduli of kenaf and ramie fibers with timber and contrast of these parameters with those of carbon and glass fibers should be seriously studied to establish the viability of using these natural fibers as reinforcement for timber. 
Instead of the constant research focus on CFRP (Carbon Fibre Reinforced Polymer) and GFRP (Glass Fibre Reinforced Polymer) as potential reinforcing materials for structural timber strengthening, more attention should now perhaps be given to the possibility of using KFRP (Kenaf Fibre Reinforced Polymer) and RFRP (Ramie Fibre Reinforced Polymer).

The authors would like to thank Universiti Teknologi Malaysia for funding this research and UTM Research Management Centre (RMC) for managing the research activities under Vot 13J89.

\section{References}

1. J.G. Teng, J.F. Chen, L. Lam, FRP-strengthened RC structures (John Wiley \& Sons, West Essex, 2002)

2. H. Saadatmanesh, A.M. Malek, J. of Composites for Con. 2, 4 (1998)

3. American Concrete Society (ACI), (ACI-440 Committee, Detroit)

4. The Concrete Society, Technical Report No. 55 (The Concrete Society, Surrey, 2012)

5. P. de la R. García, A.C. Escamilla, M.N.G. García, Composites: Part B 55 (2013)

6. Y. Nadir, P. Nagarajan, M. Ameen, Con. Build. Mat. 112 (2016)

7. J. Fiorelli, A.A. Dias, Materials Res. 6, 2 (2003)

8. M. Yahyaei-Moayyed, F. Taheri, Compos. Struct. 93 (2011)

9. J. Fiorelli, A.A. Dias, Mat. and Struct. 44 (2011)

10. ASTM, Standard Test Methods for Properties of Continuous Filament Carbon and Graphite Fiber Tows ASTM D4018-99 (ASTM International, West Conshohocken, 2017) 